then we need to know that the advice given is sound and that it is effective in changing attitudes, in reducing delay in diagnosis, and-ultimately-in reducing mortality, and especially mortality in youth and middle age. The Cancer Research Campaign has recently allocated some of its funds to support research projects concerned with cancer education, so that finance is available for evaluation. Short of money, the NHS needs to make the best use of existing knowledge; and prevention offers the best hope of reducing both the toll of cancer and the demands it makes on resources.

1 Public Education about Cancer: Research Concepts and Theoretical Findings, UICC Monograph Series vol 5. Berlin, Springer-Verlag, 1967.

2 Doll, R, Fournal of the Royal College of Physicians, 1977, 2, 125.

3 Todd, G F, Social Class Variations in Cigarette Smoking and in Mortality from Associated Diseases. London, Tobacco Research Council, 1976.

4 Strax, P, Venet, L, and Shapiro, S, American fournal of Roentgenology, $1973,117,686$

5 Stark, A M, and Way, S, Cancer, 1974, 33, 1671.

\section{Congenital dislocation of the hip}

Growth and development of the hip joint depends upon congruous and stable articulation of its components if it is to proceed normally. If the joint is unstable-as occurs ${ }^{12}$ in three to six infants per 1000 live births-the abnormality must be recognised in neonatal life so that treatment can be given to prevent hip deformity.

The simple clinical methods of detection described by Ortolani $^{3}$ and Barlow ${ }^{4}$ have gained general acceptance, but despite this several hip dislocations still go unrecognised at birth. ${ }^{156}$ Poor technique may account for some errorsexamining a baby who is not relaxed or who is lying on a soft rather than a firm surface. If traction is applied to the limb rather than pressure on the thigh the hip may be fully abducted with an unstable hip reduced. ${ }^{6}$ But perhaps most important of all is failure to recognise limitation of abduction as a sign of congenital dislocation. ${ }^{2} 78$ In infants with frank dislocation, as opposed to subluxation or instability, the "clunk" sign may be absent, and the only abnormal finding may be that both hips show restriction of abduction in flexion.?

Diagnostic success depends on organisation-clearly easier to achieve in a large maternity unit than in a small peripheral one, or after domiciliary delivery. ${ }^{9}$ As $94 \%$ of births now take place in hospital in England and Wales ${ }^{10}$ the onus must be on the hospitals to provide this service. In a well-organised unit the missed dislocation rate may be as low as 1 in 8000 births. $^{9}$ Diagnostic accuracy of this order does, however, demand a high degree of perseverance and enthusiasm on the part of the examiner: it is unlikely if screening is left to junior staff whose posts are frequently changing.

In general, the outlook for infants diagnosed and treated from birth is excellent. In a long-term follow-up of 111 children treated early by splints Fredensborg" ${ }^{11}$ reported that all developed normal hips, apart from two who had minor deformities. Mitchell ${ }^{1}$ showed that $92 \%$ of abnormal hips developed satisfactorily with splinting from birth, and similar findings were reported by Williamson. ${ }^{6}$ Later diagnosis means more complex operations, and with such a high degree of success with relatively simple treatment in the neonatal period there is a natural tendency to overtreat. ${ }^{12}$ Nevertheless, though infrequent, the complications of splinting are serious.
Gore $^{13}$ described six patients who developed avascular necrosis of the opposite normal hip while being treated for unilateral dislocation by plaster casts; the dislocated hips also became avascular. The important safeguard is to avoid extremes of abduction. If there is some pelvic obliquity it may limit hip abduction and produce shortening of the leg, and in these cases splinting may lead to ischaemic necrosis of the femoral head, ${ }^{14}$ when simple abduction exercises would have been enough.

"Clicks" as opposed to the visible and audible Ortolani jerk or "clunk" are often a source of confusion. The former are usually of no importance, disappearing within a few weeks. For example, in one series of infants examined shortly after birth 138 were diagnosed as having subluxating hips. ${ }^{15}$ At a second examination at 7-10 days 62 were still abnormal, but by 3 weeks only three infants were considered to need treatment, and those were splinted. The high incidence of abnormality noted initially appeared to be due to the ease with which clicks may be elicited in the joints of the newborn. These infants do not require treatment, but they should be examined again at the age of 3 months and at 1 year.

The importance of early diagnosis cannot be overemphasised, but even with the greatest care the occasional unexplained failure to detect instability or dislocation will occur. ${ }^{156}$ To reduce to a minimum the delay before treatment starts ideally all children should be screened again during their first year.

${ }^{1}$ Mitchell, G P, fournal of Bone and foint Surgery, 1972, 54B, 4.

2 Paterson, D C, Clinical Orthopaedics and Related Research, 1976, 119, 28.

3 Ortolani, M, Pediatria (Naples), 1937, 45, 129.

${ }^{4}$ Barlow, T G, Fournal of Bone and foint Surgery, 1962, 44B, 292.

${ }^{5}$ Owen, R, Fournal of Bone and Foint Surgery, 1968, 50B, 453.

6 Williamson, J, fournal of Bone and foint Surgery, 1972, 54B, 13

${ }^{7}$ Lloyd-Roberts, G C, and Swann, M, Fournal of Bone and foint Surgery, 1966, 48B, 666.

${ }^{8}$ Ortolani, M, Clinical Orthopaedics and Related Research, 1976, 119, 6.

${ }^{9}$ Mitchell, G P, fournal of the Royal College of Surgeons of Edinburgh, 1977, 22, 81.

${ }^{10}$ Registrar General's Stutistical Review of England and Wales for 1973, Tables, pt II Population. London, HMSO, 1975.

11 Fredensborg, N, fournal of Bone and foint Surgery, 1976, 58B, 272.

${ }^{12}$ Fredensborg, N, and Nilsson, B E. Clinical Orthopaedics and Related Research, 1976, 119, 89.

${ }^{13}$ Gore, D R, fournal of Bone and foint Surgery, 1974, 56A, 493.

${ }^{14}$ Lloyd-Roberts, G C, Orthopaedics in Infancy and Childhood, p 210. London, Butterworths, 1971.

${ }^{15}$ Nelson, M A, Fournal of Bone and foint Surgery, 1966, 48B, 388.

\section{Steroid-antibiotic combinations}

Ointments and creams containing a corticosteroid in combination with an antibiotic are prescribed widely by general practitioners and only slightly less often by most dermatologists. Many authors have, however, put forward objections to the practice, which have been more or less soundly supported by theoretical argument or by apparently reliable experimental evidence. It is accepted that there is no advantage in adding a corticosteroid to an antibiotic for treating a primary skin infection such as impetigo. On the other hand, a corticosteroidantibiotic combination is the treatment of choice in eczema of any type when there are clinical signs of bacterial infection. The controversy concerns those common cases in which eczema is not obviously infected: does the addition of an antibiotic or other antibacterial agent to a corticosteroid significantly accelerate the response to treatment? If it does, is the 
benefit great enough to outweigh the possible risk of sensitising the patient to the antibiotic or of adding new recruits to the army of antibiotic-resistant strains of bacteria ? It has proved surprisingly difficult to answer these questions acccurately.

The lesions of eczema, particularly in atopic subjects, are very readily colonised by staphylococci, and even the normal skin of patients with eczema carries a larger bacterial population than that of controls. It has been assumed that the moist conditions in the lesions favour bacterial multiplication and that treatment should be "directed at the skin lesions rather than at eradication of microorganisms." Eczema does indeed favour colonisation and multiplication, but the critical question is whether such colonisation increases the severity or duration of the lesions so that they can logically be regarded as "infected." Kligman and his colleagues in Philadelphia ${ }^{2}$ have proposed that "a lesion can be said to be infected when the burden of Staphylococcus aureus is great enough to add to morbidity in some demonstrable way." In a series of quantitative investigations ${ }^{3}$ they found that the lesions in children with atopic dermatitis improved appreciably after the application of neomycin $1 \%$ only when the pretreatment burden was over $10^{6}$ Staph aureus $/ \mathrm{cm}^{2}$. They concluded that Staph aureus is likely to be aggravating the primary disease when the count exceeds this figure. In further studies, in which the bacterial population of lesions was increased by occluding the lesions with polyethylene, they obtained additional support for this conclusion. The authors emphasise the important practical observation that with a staphylococcal load of $10^{6} / \mathrm{cm}^{2}$ there is no clinical evidence of infection: crusting and pus develop only with very much higher counts. The results of symmetrical paired comparison trials that failed to show any significant benefit from the addition of neomycin to a corticosteroid ${ }^{4}$ are not valid because effective amounts of antibiotic can be transferred on the fingers from the treated to the untreated side. ${ }^{5}$

Neomycin is the antibiotic most often used in proprietary combinations with a corticosteroid, but it has a bad reputation among dermatologists as a contact sensitiser. A critical review of published reports ${ }^{2}$ suggests that the risk of contact dermatitis is important, especially in eczema of the lower leg and when application is long continued. The short-term application of neomycin, particularly in children, seems, however, to carry little risk of sensitisation.

The risk of inducing neomycin-resistant strains of Staphylococcus is certainly a consideration in closed communities, but the evidence leads Leyden and Kligman ${ }^{2}$ to the conclusion that in outpatient practice (and in general practice) the risk is very small. This recent paper by Leyden and Kligman, ${ }^{2}$ the latest report on an important and continuing research project, provides invaluable guidance for the practitioner. Moreover, the findings have been fully confirmed by other workers in a multicentre clinical trial. ${ }^{6}$ Recommendations for the scientific management of secondarily infected dermatoses may be summarised as follows:

Firstly, the secondary infection of eczema may be clinically evident as impetiginous crusting or pustulation, but substantial infection may none the less be present in the absence of such changes. It is seldom possible to obtain quantitative bacteriological reports as a routine procedure, but semi-quantitative reports are often provided. Clinical evidence of infection or a report that Staph aureus is present in abundance will justify prescribing a corticosteroid-antibiotic combination.

Secondly, for dermatoses infected with Staph aureus neomycin will usually be the antibiotic of choice. The corticosteroid-antibiotic combination should be applied for no longer than seven to 10 days, after which it may, if necessary, be replaced by a corticosteroid alone. Intermittent resumption of the combination may be desirable, particularly in atopic children. But prolonged continuous application should be avoided, as should any application of neomycin to eczema or ulcers of the lower leg.

Lastly, combinations of corticosteroids with other antibiotics or antimicrobial agents may be indicated if Gramnegative rods or candida are present. The same general principles hold good: the combination should be applied for only a short period, after which it may be replaced, if necessary, by a steroid alone.

1 Noble, W C, and Somerville, D A, Microbiology of Human Skin, p 256. London, Saunders, 1974.

2 Leyden, J J, and Kligman, A M, British fournal of Dermatology, 1977, 96, 179.

${ }^{3}$ Leyden, J J, Marples, R, and Kligman, A M, British fournal of Dermatology, $1974,90,525$.

${ }^{4}$ Davis, C M, Fulghum, D D, and Taplin, D, fournal of the American Medical Association, 1968, 203, 298.

5 Marples, R R, and Kligman, A M, British fournal of Dermatology, 1973, 88, 61 .

${ }^{6}$ Wachs, G N, and Maibach, H, British fournal of Dermatology, 1976, 95, 323.

\section{Food and the handling of drugs}

Food and nutritional state have recently been recognised as important factors in both the absorption and metabolism of drugs. Drugs given by mouth are absorbed mainly from the small intestine, where a large surface area facilitates passive diffusion, and the rate of drug absorption depends mainly on the rate of gastric emptying. ${ }^{2}$ The presence of food in the stomach delays the speed with which drugs reach the general circulation and postpones the effects of those (such as analgesics and hypnotics) that are meant to have immediate actions. This effect does not matter when drugs are given repetitively, because the rate (as opposed to the extent) of absorption has no influence on "steady-state" concentrations during long-term treatment. ${ }^{3}$ Indeed, administration with food may be helpful for patients taking drugs that cause local irritation of the gastric mucosa. Despite this generalisation, a few drugs (such as acid-labile penicillins) are destroyed in the acid environment of the stomach or are metabolised by the gastric mucosa ${ }^{4}$ (levodopa): in these instances food may reduce both the rate and the extent of absorption. ${ }^{2}$

A few drugs which resemble certain dietary constituents undergo active transport across the small intestinal mucosa. Of those, $\alpha$-methyldopa and levodop $\mathrm{a}^{5}$ are the most important, and though high protein diets might be expected to reduce their effectiveness (by competition for active transport with other amino-acids) no systematic studies appear to have been undertaken.

Many drugs are completely absorbed from the gastrointestinal tract but are then extensively metabolised in the small intestinal wall or the liver before reaching the general circulation. This process ${ }^{6}$ of "first-pass elimination" is known to reduce the systemic availability of propranolol, oxprenolol, isoprenaline, lignocaine, aspirin, and paracetamol. In rats the activities of drug oxidising enzymes in the intestinal mucosa have been shown ${ }^{78}$ to be increased by feeding the animals with sprouts, cauliflower, and other vegetables as well as by benzo(a)pyrine-a constituent of both cigarette smoke and charcoal-grilled meat. Recently, Conney and 